\title{
Dynamics of plasmid transfer on surfaces
}

\author{
LONE SIMONSEN \\ Department of Zoology, University of Massachusetts, Amherst, MA 01003, USA
}

(Received 28 July 1989; revised 13 December 1989; accepted 5 March 1990)

\begin{abstract}
A protocol was developed to study the dynamics of growth and plasmid transfer in surface populations of bacteria. This method allows for quantitative estimates of cell population densities over time, as well as microscopic observations of colony growth and interactions. Using this 'surface slide system' (SSS), the dynamics of the plasmid R1 and its permanently derepressed mutant R1drd19 in surface cultures of Escherichia coli K12 was examined. In surface culture, the stationary-phase cell densities were constant over a wide range of initial cell density (= colony density) and comparable to those obtained in liquid culture. For high initial cell densities, where the cells formed a confluent layer at stationary phase, the kinetics of growth and plasmid transfer was similar to that obtained in liquid culture, and the relative yields of R1drd19 and R1 transconjugants were similar in the two habitats. In surface culture, however, R1drd19 transconjugant yield was profoundly affected, and R1 transfer to a lesser extent, by colony density. In contrast, liquid matings were virtually unaffected by initial cell density. The transfer advantage of the permanently derepressed over the repressed plasmid was much less apparent for lower colony densities. I propose a hypothesis for plasmid transfer between colonies that explains these observations as a consequence of the geometry of the surface habitat and the effect of transitory derepression of the synthesis of pili.
\end{abstract}

\section{Introduction}

Conjugative plasmids have two modes of reproduction: by propagation along with the bacterial host and by infectious transfer to new hosts. A plasmid's representation in future generations of bacteria, its fitness, is therefore determined by its capacity for vertical as well as horizontal transmission. If these accessory elements do not carry genes that confer a fitness advantage upon their hosts (e.g. antibiotic resistance), the cost of plasmid carriage and the loss of plasmids by vegetative segregation must be offset by infectious transfer (Stewart \& Levin, 1977). However, empirical studies indicate that the transfer rates of naturally occurring plasmids are too low to balance these costs, suggesting that plasmids can only be maintained in bacterial populations by carrying genes that increase host fitness (Levin \& Lenski, 1983). There is a major caveat to this interpretation: most empirical studies and formal theory of plasmid transfer kinetics have been restricted to populations of bacteria growing in well-agitated liquid culture. Under these conditions, the kinetics of plasmid transfer is described by a simple mass-action model that assumes randomly

Abbreviation: SSS, surface slide system. distributed, homogeneous populations of planktonic donor and recipient cells (Levin et al., 1979).

In natural habitats, however, most bacteria are attached to surfaces and grow as microcolonies (Brock, 1971; Caldwell et al., 1981; Costerton et al., 1987; Fraleigh \& Bungay, 1986; Nowicki et al., 1985; Pirt, 1967; Shapiro, 1985, 1987; Wimpenny \& Parr, 1979). On first consideration it would seem that the dynamics of plasmid transfer in surface populations of bacteria would be much more complex than in liquid. Bacteria growing as colonies are fixed in space and thus represent a clustered population of cells that do not have equal opportunity to participate in mating events. Also, physiological heterogeneity results from the cells within a colony experiencing different environmental conditions (Pirt, 1967; Shapiro, 1985, 1987; Wimpenny \& Parr, 1979), and physiological state is known to influence plasmid transfer rates (Levin et al., 1979).

As a consequence of the lack of experimental and mathematical models for surface populations, it is not known how the physical structure of the habitat will affect conclusions about the population biology of plasmids. Are the dynamics of plasmid transfer in surface populations fundamentally different from those in liquid?

To address this question, a procedure was developed 
for studying the population biology of bacteria living on surfaces. Using this 'surface slide system', for convenience designated SSS, the population dynamics of Escherichia coli $\mathrm{K} 12$ and the plasmid $\mathrm{R} 1$ and its derepressed mutant $\mathrm{R} 1 d r d 19$ were examined.

\section{Methods}

Bacteria and plasmids. E. coli $\mathrm{K} 12$ strain $\mathrm{J} 53$ (met pro $\lambda^{+}$) hosting R1 $(\mathrm{Cm}, \mathrm{Km}, \mathrm{Ap}, \mathrm{Sm}, \mathrm{Su}$ ) or its permanently derepressed mutant $\mathrm{R} 1 d r d 19$ was used as the plasmid donor, and a nalidixic acid resistant mutant of E. coli $\mathrm{CSH} 50[\Delta($ lac-pro) ara str nal $]$ (Miller, 1972) was the recipient in all experiments. The prototrophic $E$. coli K12 strain MICR40 (lacZ $r p s L$ ) (Newton, 1970) was employed in an experiment designed to determine the contribution of Difco agar as a carbon source.

Media. Total cell densities were estimated by dilution in $0.85 \% \mathrm{NaCl}$ and plating on tetrazolium lactose (TL) agar (Levin et al., 1979); on this medium, the $\mathrm{Lac}^{+}$donor colonies appear white and the $\mathrm{Lac}^{-}$recipients red. Transconjugant densities were estimated using TLCN plates: TL agar containing $25 \mathrm{mg} \mathrm{l}^{-1}$ chloramphenicol and $20 \mathrm{mg} \mathrm{l}^{-1}$ nalidixic acid. When necessary, TLC was used for determining donor densities, and recipients were distinguished from transconjugants by toothpicking $\mathrm{Lac}^{-}$colonies from TL onto TLCN plates.

All liquid cultures were grown in a glucose-limited minimal salts medium, DM, containing, per litre: $7 \mathrm{~g} \mathrm{~K}_{2} \mathrm{HPO}_{4}, 2 \mathrm{~g} \mathrm{K \textrm {KH } _ { 2 }} \mathrm{PO}_{4}, 1 \mathrm{~g}$ $\left(\mathrm{NH}_{4}\right)_{2} \mathrm{SO}_{4}, 0.5 \mathrm{~g}$ sodium citrate $2 \mathrm{H}_{2} \mathrm{O}, 40 \mathrm{mg}$ proline, $40 \mathrm{mg}$ methionine, $0 \cdot 1 \mathrm{~g} \mathrm{Mg}_{2} \mathrm{SO}_{4} \cdot 7 \mathrm{H}_{2} \mathrm{O}, 2 \mathrm{mg}$ thiamin and $300 \mathrm{mg}$ glucose. The vitamin, amino acids and sugar were added after autoclaving. For SSS cultures, Bacto-agar (Difco) $\left(16 \mathrm{~g} \mathrm{l}^{-1}\right)$ was added to DM medium.

Experimental procedures. The liquid culture experiments were carried out in $50 \mathrm{ml}$ Erlenmeyer flasks containing $10 \mathrm{ml}$ DM medium, inoculated from overnight cultures, and shaken at 170 r.p.m. at $37^{\circ} \mathrm{C}$.

The SSS cultures were prepared by pipetting $2 \mathrm{ml}$ of DM agar over the entire surface of sterile microscope slides $(25 \times 75 \mathrm{~mm})$ placed in glass Petri dishes. These cultures were inoculated by spreading $50 \mu \mathrm{l}$ of a cell suspension over the hardened and dry agar surface, and then incubated at $37^{\circ} \mathrm{C}$ in airtight boxes. Less than 5 min elapsed from mixing the donor and recipient cultures until the slides were dry. The slides were sampled by transferring the agar to dilution tubes containing $10 \mathrm{ml} 0.85 \% \mathrm{NaCl}$, which were then vortexed at high speed for $20 \mathrm{~s}$ to suspend the cells. Cell density was defined as cells per $\mathrm{ml}$ agar, and therefore densities estimated from the harvesting tubes were multiplied by five $(10 \mathrm{ml} / 2 \mathrm{ml}$; the agar is not in solution).

To explore the kinetics of plasmid transfer on surfaces, 14 SSS cultures were inoculated with $1 \times 10^{7}$ cells per slide, with donors [J53(R1drd19)] and recipients (CSH50) in a $1: 1$ ratio. For the experiments examining the effects of initial cell density, five SSS and two liquid cultures were inoculated for each density. Overnight cultures of donors and recipients were diluted, mixed $1: 1$, and $50 \mu \mathrm{l}$ of the mating mixtures was applied to each slide and $250 \mu \mathrm{l}$ to each flask. Cultures were incubated for about $30 \mathrm{~h}$, until stationary phase was reached and growth and plasmid transfer ceased.

Density definition. Cell density in the surface habitat was defined as cells per unit volume of medium. Justification for this solution to the problem of comparing two- and three dimensional habitats will be presented in the Discussion.
Table 1. SSS calibration: the recovery of a known amount of donor and recipient cells

Eight SSS and eight liquid cultures were inoculated with $0.1 \mathrm{ml}$ of a $1000 \times$ diluted overnight culture of CSH50 and incubated at $37^{\circ} \mathrm{C}$. The cultures were then harvested and plated. The experiment was repeated with J53(R1drd19).

\begin{tabular}{lll}
\hline \hline Cell line & Habitat & $\begin{array}{c}\text { Recovery } \pm \text { SE } \\
\text { (cells ml }{ }^{-1} \text { ) }\end{array}$ \\
\hline CSH50 & Liquid & $1.8 \times 10^{5} \pm 0.22 \times 10^{5}$ \\
& Surface & $1.7 \times 10^{5} \pm 0.24 \times 10^{5}$ \\
J53(R1drd19) & Liquid & $1.8 \times 10^{5} \pm 0.21 \times 10^{5}$ \\
& Surface & $1.7 \times 10^{5} \pm 0.10 \times 10^{5}$ \\
\hline
\end{tabular}

\section{Results}

\section{Calibration of the SSS method}

Since the SSS method involves harvesting and sampling cells on agar, experiments were performed to (i) evaluate the efficiency of the procedure used to recover the bacteria from the surfaces, (ii) determine the stability of stationary-phase population densities, (iii) demonstrate that glucose was the limiting carbon source, (iv) ascertain the contribution of agar as a carbon source, and (v) demonstrate that transconjugants obtained were formed in the SSS cultures, and not during the sampling or plating procedure.

(i) Slides were seeded with approximately $10^{3} \mathrm{CSH} 50$ cells and incubated for $30 \mathrm{~h}$. The agar was suspended and vortexed repeatedly for a total of $120 \mathrm{~s}$. Cell densities were estimated after $5,10,20,30,60$ and $120 \mathrm{~s}$ vortexing. The density of recovered cells increased during the first $10 \mathrm{~s}$ of vortexing, and thereafter remained constant. This experiment was repeated for the donor strain J53(R1drd19) and the same result obtained.

To determine the recovery efficiency of cells from the SSS cultures, eight slides and eight liquid cultures were inoculated with the same number of cells and harvested after $1 \mathrm{~h}$ incubation while still in lag phase; the liquid cultures were controls for cell mortality in lag phase. For both the donor and recipient cell lines, the mean recovery from the SSS cultures was not significantly different from that of liquid culture ( $t$-test: CSH50, $t=0.35, P>0.50$; J53(R1drd19), $t=0.57, P>0.50$ ) (Table 1).

(ii) To establish whether changes in population density and composition occur during stationary phase in mating experiments, corresponding SSS and liquid cultures were inoculated with the same mating mixture of CSH50 and J53(R1drd19) and incubated for 24,48 and $72 \mathrm{~h}$. Stationary-phase cell densities of the donor, recipient and transconjugant populations did not change during this time in either habitat. 
(iii) To determine whether glucose at $300 \mu \mathrm{g} \mathrm{ml}^{-1}$ was the limiting carbon source, corresponding SSS and liquid cultures containing varying concentrations of glucose in the range $50-800 \mu \mathrm{g} \mathrm{ml}^{-1}$ were inoculated with about $10^{5}$ CSH50 cells. At stationary phase, the surface cultures were harvested as usual, whereas the cell densities of the liquid cultures were estimated by measurements of $\mathrm{OD}_{675}$. Stationary-phase cell densities were a linear function of the glucose concentration in both habitats, with a slope of $0.8 \pm 0.05$ in the surface and $0.8 \pm 0.04$ in the liquid cultures (means $\pm \mathrm{SE}$ ). The linear relationship indicated that glucose is limiting in that range.

(iv) To ascertain the contribution of Difco agar as a carbon source, eight SSS and eight liquid cultures without glucose and amino acids were inoculated with approximately $10^{3}$ cells $\mathrm{ml}^{-1}$ of the prototrophic strain MICR40. The estimated cell densities at stationary phase were (means $\pm \mathrm{SE}$ ) $2.6 \pm 0.44 \times 10^{7} \mathrm{ml}^{-1}$ on surfaces and $6.4 \pm 1.3 \times 10^{5} \mathrm{ml}^{-1}$ in the liquid culture (agarfree control). This result shows that Difco agar provides sufficient carbon source to support growth of $3 \times 10^{7}$ cells $\mathrm{ml}^{-1}$.

(v) One SSS culture was inoculated with about $1 \times 10^{6}$ J53(R1drd19) cells and another with the same initial density of CSH50 cells. At stationary phase, the two slides were transferred to the same dilution tube and vortexed for $20 \mathrm{~s}$. After $5 \mathrm{~min}, 100 \mu \mathrm{l}$ of cell suspension was spread onto TLCN plates. No transconjugants were obtained.

From these calibration experiments, I conclude: (i) That $20 \mathrm{~s}$ of vortexing is sufficient to recover nearly $100 \%$ of the cells from SSS cultures. (ii) The exact time for sampling a stationary phase liquid or SSS culture is not critical, since the densities of donors, recipients and transconjugants remain constant for at least $48 \mathrm{~h}$ after cultures enter stationary phase. (iii) That glucose, at $300 \mu \mathrm{g} \mathrm{ml}^{-1}$, is the limiting carbon source in both habitats. (iv) Difco agar supports the growth of $3 \times 10^{7}$ cells $\mathrm{ml}^{-1}$, about $10 \%$ of the stationary-phase cell yield in the DM agar medium employed in all experiments. (v) No plasmid transfer takes place while sampling and plating the stationary phase cultures.

\section{The kinetics of plasmid transfer on surfaces}

One way of comparing the dynamics of plasmid transfer in surface and liquid culture is to observe the change in transconjugant population densities over time in an exponentially growing batch culture. According to the model of plasmid transfer developed for liquid culture, the change in the density of transconjugants $(T)$ is due to their growth, and recruitment from the recipient population $(R)$, by horizontal transfer from the original

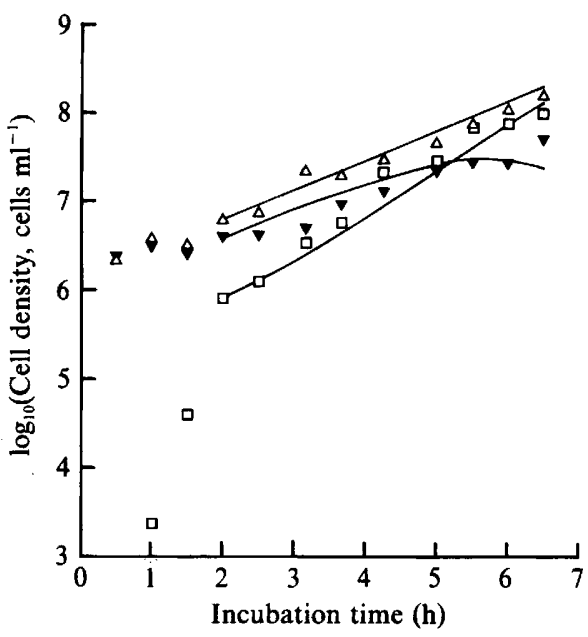

Fig. 1. A mass-action fit of the kinetics of a surface mating at high initial density for J53(R1drd19) $\times$ CSH50. The points represent the observed cell densities (cells per ml medium) for the three populations: donors $(\triangle)$, recipients $(\nabla)$ and transconjugants $(\square)$. The solid lines were derived by numerical solution of the equations for a mass-action model of plasmid transfer (Levin et al., 1979). The exponential growth rate, $\psi$, was estimated to be $0.76 \mathrm{~h}^{-1}$ and the rate constant of plasmid transfer, $\gamma, 5 \cdot 0 \times 10^{-9} \mathrm{ml} \cdot \mathrm{cell}^{-1} \cdot \mathrm{h}^{-1}$.

donors $(D)$ and transconjugants (Levin et al., 1979):

$$
\mathrm{d} T / \mathrm{d} t=\psi \cdot T+\gamma \cdot(D+T) \cdot R
$$

where $\psi$ is the growth rate and $\gamma$ is the transfer rate constant.

The results of the kinetic surface experiment using the plasmid R1drd19 (Fig. 1) appeared to be very similar to the kinetics previously obtained in liquid culture (Levin et al., 1979). This visual impression was supported by calculating the growth and transfer rate parameters $\left(\psi=0.76 \mathrm{~h}^{-1}\right.$ and $\left.\gamma=5.0 \times 10^{-9} \mathrm{ml} \cdot \operatorname{cell}^{-1} \cdot \mathrm{h}^{-1}\right)$ and comparing the observed change in the three populations during the exponential growth phase with that predicted using numerical solutions to the equations (1), (2) and (3) in Levin et al. (1979) (Fig. 1). Although the assumption of the mass-action model of randomly distributed, equally accessible cells is certainly not met in the surface-mating populations, the estimates of growth and transfer rates, as well as the fit of the model, are very similar to those obtained in liquid by Levin et al. (1979) $\left(\psi=0.86 \mathrm{~h}^{-1}\right.$ and $\left.\gamma=3.8 \times 10^{-9} \mathrm{ml} \cdot \mathrm{cell}^{-1} \cdot \mathrm{h}^{-1}\right)$. The initial densities of donor and recipient cells employed in this experiment resulted in a confluent cell layer at stationary phase (microscopic observation). To explore the generality of the apparent mass-action fit, further experiments were carried out where the initial cell densities were varied. Since one inoculated cell gives rise to one colony, varying initial density determines both the number and size of the colonies at stationary phase. 
Table 2. Effect of initial cell density on bacterial growth and plasmid transfer in surface and liquid culture

Stationary-phase densities (cells per ml medium) for donors, recipients, transconjugants and total cells as a function of initial cell density are shown for mating experiments with R1 and R1drd19. The mean values of four or five SSS cuitures and two liquid cultures are reported. The standard errors of the surface estimates were approximately $10 \%$ of the mean, except for the transconjugant yield in surface culture; see error bars in Fig. 2(b).

\begin{tabular}{|c|c|c|c|c|c|c|c|c|c|}
\hline \multicolumn{10}{|c|}{ Stationary-phase cell densities (cells $\mathrm{ml}^{-1}$ ) } \\
\hline \multicolumn{5}{|c|}{ Surface mating $J 53(R I) \times C S H 50$} & \multicolumn{5}{|c|}{ Liquid mating $J 53(R I) \times C S H 50$} \\
\hline $10^{7}$ & $3.8 \times 10^{8}$ & $1.5 \times 10^{8}$ & $2 \cdot 1 \times 10^{5}$ & $5.2 \times 10^{8}$ & $10^{7}$ & $2 \cdot 2 \times 10^{8}$ & $9.8 \times 10^{7}$ & $4.4 \times 10^{3}$ & $3.1 \times 10^{8}$ \\
\hline $10^{6}$ & $3 \cdot 1 \times 10^{8}$ & $1.8 \times 10^{8}$ & $2 \cdot 1 \times 10^{5}$ & $4.8 \times 10^{8}$ & $10^{6}$ & $1.7 \times 10^{8}$ & $8.5 \times 10^{7}$ & $5.9 \times 10^{3}$ & $2.6 \times 10^{8}$ \\
\hline $10^{5}$ & $2.2 \times 10^{8}$ & $1.8 \times 10^{8}$ & $6.5 \times 10^{4}$ & $4 \cdot 1 \times 10^{8}$ & $10^{5}$ & $2.0 \times 10^{8}$ & $6.9 \times 10^{7}$ & $7.9 \times 10^{3}$ & $2.7 \times 10^{8}$ \\
\hline $10^{4}$ & $2.7 \times 10^{8}$ & $1.9 \times 10^{8}$ & $3.0 \times 10^{4}$ & $4.6 \times 10^{8}$ & $10^{4}$ & $2.7 \times 10^{8}$ & $6 \cdot 1 \times 10^{7}$ & $1.6 \times 10^{4}$ & $2.7 \times 10^{8}$ \\
\hline $10^{3}$ & $2 \cdot 7 \times 10^{8}$ & $1.9 \times 10^{8}$ & $3.0 \times 10^{4}$ & $4.6 \times 10^{8}$ & $10^{3}$ & $2.9 \times 10^{8}$ & $4.9 \times 10^{7}$ & $1.9 \times 10^{4}$ & $2.9 \times 10^{8}$ \\
\hline $10^{2}$ & $2.9 \times 10^{8}$ & $2 \cdot 2 \times 10^{8}$ & $1.6 \times 10^{4}$ & $5 \cdot 0 \times 10^{8}$ & $10^{2}$ & $4 \cdot 1 \times 10^{8}$ & $1.0 \times 10^{7}$ & $6.0 \times 10^{3}$ & $4.1 \times 10^{8}$ \\
\hline \multicolumn{6}{|c|}{ Surface mating J53(RIdrd19) $\times$ CSH5O } & \multicolumn{4}{|c|}{ Liquid mating $J 53(R 1 d r d 19) \times C S H 50$} \\
\hline $10^{7}$ & $6.6 \times 10^{7}$ & $1.7 \times 10^{8}$ & $9.4 \times 10^{7}$ & $3.3 \times 10^{8}$ & $10^{7}$ & $1.2 \times 10^{8}$ & $6.8 \times 10^{7}$ & $7.4 \times 10^{7}$ & $2.6 \times 10^{8}$ \\
\hline $10^{6}$ & $1.4 \times 10^{8}$ & $2.5 \times 10^{8}$ & $4.4 \times 10^{7}$ & $4.4 \times 10^{8}$ & $10^{6}$ & $1.7 \times 10^{8}$ & $3.7 \times 10^{7}$ & $8.4 \times 10^{7}$ & $2.9 \times 10^{8}$ \\
\hline $10^{5}$ & $1.4 \times 10^{8}$ & $1.9 \times 10^{8}$ & $8.0 \times 10^{6}$ & $3.4 \times 10^{8}$ & $10^{5}$ & $1.7 \times 10^{8}$ & $2.7 \times 10^{7}$ & $7.4 \times 10^{7}$ & $2.7 \times 10^{8}$ \\
\hline $10^{4}$ & $1.6 \times 10^{8}$ & $2 \cdot 3 \times 10^{8}$ & $1.8 \times 10^{6}$ & $3.9 \times 10^{8}$ & $10^{4}$ & $1.9 \times 10^{8}$ & $1.8 \times 10^{7}$ & $6.6 \times 10^{7}$ & $2.7 \times 10^{8}$ \\
\hline $10^{3}$ & $2 \cdot 3 \times 10^{8}$ & $2.6 \times 10^{8}$ & $4.7 \times 10^{5}$ & $4.9 \times 10^{8}$ & $10^{3}$ & $2.3 \times 10^{8}$ & $7.4 \times 10^{6}$ & $4.7 \times 10^{7}$ & $2.8 \times 10^{8}$ \\
\hline $10^{2}$ & $2.4 \times 10^{8}$ & $2.2 \times 10^{8}$ & $4.1 \times 10^{4}$ & $4.7 \times 10^{8}$ & $10^{2}$ & $2.6 \times 10^{8}$ & $3.7 \times 10^{6}$ & $1.2 \times 10^{7}$ & $2.8 \times 10^{8}$ \\
\hline
\end{tabular}

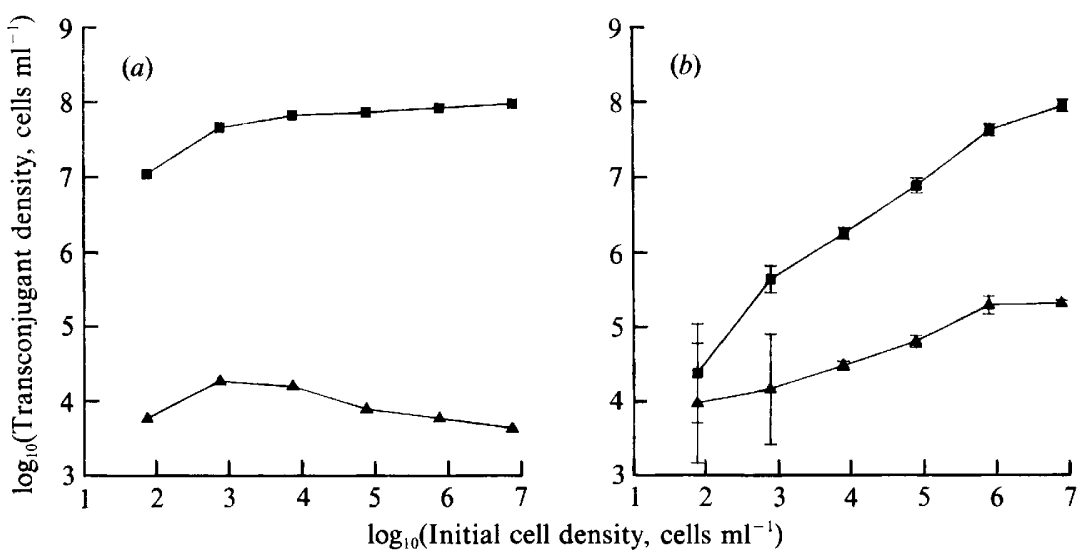

Fig. 2. Dynamics of surface and liquid matings for the plasmids $\mathrm{R} 1$ and $\mathrm{R} 1$ drd 19 for different initial densities. Transconjugant production (cells per ml medium at stationary phase) in (a) liquid cultures and $(b)$ surface cultures is shown. The plotted points for the liquid cultures represent means; those for the surface cultures represent means $\pm 2 \times$ SE. $\square$, Matings with R1drd19; $\Delta$, matings with R1.

\section{The influence of colony density on plasmid transfer}

Intuitively, one would expect plasmid transfer on surfaces to depend on initial cell density, since at low densities the donor and recipient colonies may never meet. This is in contrast to liquid batch cultures where no dependence on initial cell density is expected, since most plasmid transfer takes place after the densities become large (Levin et al., 1979).

A series of SSS and liquid cultures were inoculated with varying numbers of cells and the stationary-phase cell densities of the three cell populations were determined. The total cell yield in the surface cultures was independent of the initial cell density (Table 2), and on average about $50 \%$ higher than in liquid culture. I attribute this difference to the observation that cell size is greater in liquid than in surface culture: microscopic observations of cells from liquid culture and suspended colonies showed that the former were $2-5 \mu \mathrm{m}$ in length, whereas the latter were $1-2 \mu \mathrm{m}$.

As expected, transconjugant production in the liquid cultures was largely independent of initial cell density 
(Fig. 2a). The transconjugant yield for the R $1 d r d 19$ mating was consistently about 3.5 orders of magnitude higher than that for the R1 mating (Fig. 2a). Levin et al. (1979) determined that the exponential-phase transfer rate of $\mathrm{R} 1 d r d 19$ was three orders of magnitude larger than that of R1. Therefore transconjugant yield in a batch culture provides a relative measure of the rate of plasmid transfer.

On surfaces, the transconjugant yields for $\mathrm{R} 1 d r d 19$ matings were strongly dependent on colony density: transconjugant production dropped more than three orders of magnitude from the highest to the lowest density (Fig. $2 b$ ). In the case of the repressed plasmid R1, this colony density dependence was less pronounced: transconjugant yields declined about one order of magnitude over the range of colony densities (Fig. $2 b$ ). The horizontal transfer advantage of the permanently derepressed plasmid $\mathrm{R} 1 d r d 19$ relative to $\mathrm{R} 1$ declined with colony density, and was absent at the lowest density (Fig. $2 b$ ). Thus, the great difference between $\mathrm{R} 1 d r d 19$ and R1 observed in liquid culture is much less pronounced in surface culture when colony density is low.

In liquid, donor : recipient ratios declined as initial cell density declined (Table 2), showing that the donor strains grew at a slower rate than the recipient strain in this habitat. This decline was not observed in the SSS cultures, suggesting that the donor and recipient growth rates were similar in the surface habitat (Table 2).

\section{Discussion}

The SSS method provides the means to study the dynamics of bacterial interactions in a surface habitat. The method allows a quantitative evaluation of cell population changes with the same precision as traditional liquid culture methods. In addition, since the agar layer on the SSS slides is thin, the formation and interactions of microcolonies can be observed using a phase-contrast microscope. The protocol was developed to study plasmid transfer dynamics, but can be applied to other investigations of colony-forming micro-organisms and their accessory genetic elements.

To allow comparisons with liquid culture results, population density on surfaces is defined as cells per $\mathrm{ml}$ medium, rather than per unit surface area. This definition is biologically meaningful, as the stationaryphase cell yields per $\mathrm{ml}$ medium are roughly the same in the two habitats regardless of initial densities. This is a consequence of the ability of colonies to sequester the nutrients in the surface medium over a relatively large distance.
When colony densities are high and the cells are forming a confluent layer on the surface, the kinetics of plasmid transfer is virtually indistinguishable from that in liquid, which has been shown to be described by a mass-action model (Levin et al., 1979). This apparent mass-action fit for confluent surface growth is consistent with the observations of Freter et al. (1983), who obtained a similar result for the transfer kinetics of $\mathrm{R} 1 d r d 19$ in a mouse intestine. Their result is probably a consequence of employing high cell densities, and it is not possible to conclude if the mating events actually took place between cells attached to surfaces or between suspended cells in the mouse intestines.

This apparent mass-action fit did not obtain for lower colony densities since the yield of transconjugants at stationary phase was found to be colony-densitydependent. This was especially pronounced for the derepressed plasmid R1drd19, while the wild-type plasmid Rl was less affected by decreasing colony density. For the lowest colony density, there was no horizontal transfer advantage due to permanent derepression.

I propose that these results were a consequence of the geometry of a surface habitat and the effect of transitory derepression of the synthesis of pili on the rate of $\mathrm{R} 1$ plasmid transfer: the observed decline in R1drd19 transconjugant yield must be related to fewer colonies participating in matings as colony density declines. If colony participation was the only factor responsible for the observed frequency-dependence, then the expected pattern of transconjugant production for the R1 plasmid would be a parallel line about three orders of magnitude below the R1drd19 yields. However, this is not the case; the two lines converge and eventually meet at the lowest colony density.

I suggest that R1 transconjugant yields were less affected by colony density than those of its permanently derepressed mutant $\mathrm{R} 1 d r d 19$ as a result of transitory derepression. Newly formed R1 transconjugants are transitorily derepressed for a few cell generations, and transfer at a derepressed rate until repression is reestablished (Willetts, 1974; Lundquist \& Levin, 1986). I propose the following hypothesis (Fig. 3). Upon the meeting of a recipient and $\mathrm{R} 1$ donor colony, transitorily derepressed transconjugants are formed in the interface. These will transfer the plasmid to the adjacent recipient cells at a high rate, resulting in a front of transitorily derepressed transconjugants sweeping through the recipient colony. Meanwhile, the original donor cells, as well as the transconjugants in which repression has been established, would not be in further contact with the recipient cells. This scenario of the events taking place in a colony mating will influence the overall yield of transconjugants in an SSS culture in a colony-density- 


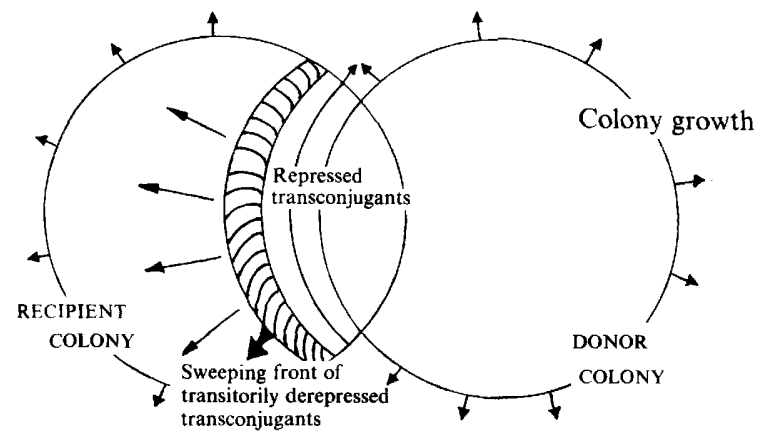

Fig. 3. A proposed model for plasmid transfer on surfaces. Upon the meeting of a donor and a recipient colony, transitorily derepressed transconjugants form in the interface and sweep through the recipient colony at a high (derepressed) rate. The importance of this effect on the overall transconjugant production in an SSS culture is colony-densitydependent.

dependent manner: When colony density is high, many colonies meet, resulting in the original donors being responsible for most transconjugant production. At low colony densities, few colonies meet, and transitorily derepressed transconjugants are the primary donors. This hypothesis is supported by the observation that transconjugant yields for $\mathrm{R} 1 d r d 19$ and $\mathrm{R} 1$ were similar at the lowest colony density, suggesting that in both cases the primary donors were derepressed.

In the case of plasmid transfer in liquid batch cultures, transitory derepression does not play a significant role, since during the growth period the derepressed transconjugants are a very small fraction of the randomly distributed donor populations (Levin et al., 1979).

Many naturally occurring conjugative plasmids have evolved mechanisms to repress conjugative pilus synthesis and thus reduce their rate of infectious transfer (Meynell, 1973; Bradley et al., 1980). The evolution of repression mechanisms has been attributed to trade-offs in the vertical component of plasmid fitness: repression reduces the energetic costs to the host resulting from the constitutive expression of the plasmid transfer genes (Levin \& Lenski, 1983) and lowers the risk of attack by pili-specific bacteriophages (Anderson, 1968). This study has shown that under conditions of low colony density, plasmids can maintain the benefits of repression without reducing their horizontal fitness component. It is therefore tempting to speculate that the evolution and maintenance of plasmid-encoded repression mechanisms is an adaptation to their bacterial hosts living in surface habitats.

This study has demonstrated that the dynamics of plasmid transfer on surfaces is qualitatively different from that in liquid. Although the surface transfer rates of $\mathrm{R} 1$ and $\mathrm{R} 1 d r d 19$ were comparable to the rates obtained in liquid culture, it is unlikely that this is a general result. In fact, plasmids that determine rigid pili are known to transfer at a much higher rate on surfaces than in liquid (Bradley et al., 1980).

In order to address questions related to the ability of plasmids to establish and spread in natural habitats in the spirit of Stewart \& Levin (1977), it is critical to develop a mathematical model of the dynamics of plasmid transfer on surfaces. I am currently developing a model that will provide a colony-density-independent estimate of the plasmid transfer rate akin to the liquid culture mass action estimate $\gamma$.

I wish to thank David M. Gordon and Bruce R. Levin for many valuable suggestions in all phases of this project, Carol Laursen for skilful technical assistance and Judy Mongold and three anonymous reviewers for help in preparation of the manuscript.

This work was supported by the US Environmental Protection Agency COOP no. CR-814309, National Institute of Health Grant GM 33782, the Danish Water Quality Institute and the Center for Microbiology, Copenhagen.

\section{References}

ANDERSON, E. S. (1968). The ecology of transferable drug resistance in the enterobacteria. Annual Review of Microbiology 22, 131-180.

Bradley, D. E., TAYlor, D. E. \& CohEN, D. R. (1980). Specification of surface mating systems among conjugative drug resistance plasmids in Escherichia coli K-12. Journal of Bacteriology 143, 1466 1470.

BRock, T. D. (1971). Microbial growth rates in nature. Bacteriological Reviews 35, 39-58.

Caldwell, D. E., Brannan, D. K., Morris, M. E. \& Betlach, M. R. (1981). Quantitation of microbial growth on surfaces. Microbial Ecology 7, 1-11.

Costerton, J. W., Cheng, K. J., Geesey, G. G., Ladd, T. I., Nickel, J. C., DasGupta, M. \& MARRIE, T. J. (1987). Bacterial biofilms in nature and disease. Annual Review of Microbiology 41, 435-464.

Fraleigh, S. P. \& Bungay, H. R. (1986). Modelling of nutrient gradients in a bacterial colony. Journal of General Microbiology 132 , 2057-2060.

FRETER, R., Freter, R. R. \& BRICHNER, H. (1983). Experimental and mathematical models of Escherichia coli plasmid transfer in vitro and in vivo. Infection and Immunity 39, 60-84.

LEVIN, B. R. \& LENSKI, R. E. (1983). Coevolution in bacteria and their viruses and plasmids. In Coevolution pp. 99-127. Edited by $\mathbf{J}$. Futuyma \& M. Slatkin. Sunderland, Massachusetts: Sinauer Associate.

LeVin, B. R., Stewart, F. M. \& Rice, V. A. (1979). The kinetics of conjugative plasmid transmission: fit of a simple mass action model. Plasmid 2, 247-260.

LuNDQUIST, P. D. \& LEVIN, B. R. (1986). Transitory derepression and the maintenance of conjugative plasmids. Genetics 113, 483-497.

Meynell, G. G. (1973). Bacterial Plasmids. Cambridge, Massachusetts: MIT Press.

MilleR, J. H. (1972). Experiments in Molecular Genetics. Cold Spring Harbor, NY: Cold Spring Harbor Laboratory.

NEWTON, A. (1970). Isolation and characterization of frameshift mutations of the lac operon. Journal of Molecular Biology 49, 589601 .

Nowicki, B., Rhen, M., Vaisanen-Rhen, V., Pere, A. \& Korhonen, T. (1985). Organization of fimbriate cells in colonies of Escherichia coli strain 3040. Journal of General Microbiology 131, 1263-1266. 
PIRT, S. J. (1967). A kinetic study of the mode of growth of surface colonies of bacteria and fungi. Journal of General Microbiology 47, $181-197$.

ShapiRo, J. A. (1985). Scanning electron microscope study of Pseudomonas putida colonies. Journal of Bacteriology 164, 1171-1181.

SHAPIRO, J. A. (1987). Organization of developing Escherichia coli colonies viewed by scanning electron microscopy. Journal of Bacteriology 169, 142-156.
StewarT, F. M. \& LeVIN, B. R. (1977). The population biology of bacterial plasmids: a priori conditions for the existence of conjugationally transmitted factors. Genetics 87, 209-228.

WiLletTS, N. S. (1974). The kinetics of inhibition of Flac transfer by R100 in E. coli. Molecular and General Genetics 129, 123-130.

W IMPENNY, J. W. T. \& PARR, J. A. (1979). Biochemical differentiation in large colonies of Enterobacter cloacae. Journal of General Microbiology 114, 487-489. 